\title{
APLICABILIDADE DA GUARDA COMPARTILHADA OBRIGATÓRIA EM FACE DA PROTEÇÃO E O MELHOR INTERESSE DOS FILHOS
}

\section{APPLICABILITY OF THE COMPULSORY JOINT CUSTODY IN VIEW OF THE PROTECTION AND BEST INTEREST OF CHILDREN}

\author{
${ }^{1}$ Edwirges Elaine Rodrigues
}

\section{RESUMO}

A presente pesquisa tem por base o estudo da guarda compartilhada, verificando sua compatibilidade com o princípio do melhor interesse dos filhos. Com o advento da Lei n. 13.058/2014, que conferiu caráter de obrigatoriedade à guarda conjunta, provocou-se enorme dissenso entre os doutrinadores, ao mencionar que o tempo de convívio entre pais e filhos deverá ser equilibrado, remetendo à uma confusão com a guarda alternada, prejudicial à prole. Destarte, o método escolhido foi o dedutivo, no qual realizou-se uma revisão da bibliografia referente ao Direito das Famílias e em especial ao instituto da autoridade parental e guarda compartilhada.

Palavras-chave: Autoridade parental, O melhor interesse dos filhos, Guarda compartilhada

\begin{abstract}
The present research has to base the joint custody study, checking its compatibility with the best interest of children's principle. With the enactment of Law n. 13,058/ 2014, which gave character obligation to joint custody, led to huge disagreement among scholars, to mention that the interaction time between parents and children must be balanced, referring to confusion with alternating custody, harmful to offspring. Thus, the chosen method was deductive, which held a review of the literature on the Law of Families and especially the Institute of parental authority and joint custody.
\end{abstract}

Keywords/Palabras-claves/Mots-clés: Parental authority, Best interest of the children, Joint custody

\section{INTRODUÇÃO}

\footnotetext{
${ }^{1}$ Mestranda em Direito pela Universidade Estadual Paulista Júlio de Mesquita Filho - FCHS-UNESP, São Paulo, SP. (Brasil). Advogada no escritório Advocacia e Consultoria Jurídica, A.C.J. (Brasil). E-mail: edwirges_elaine@yahoo.com.br.
} 
O direito brasileiro, sobretudo o direito de família, vêm enfrentando diversas transformações na contemporaneidade, atendendo aos anseios da sociedade que se modifica a cada dia. Como reflexo destas alterações, a família ganhou nova concepção, constituindo atualmente, para o Direito, um núcleo de desenvolvimento do ser enquanto pessoa humana, local de aprendizado, crescimento e participação, vocacionado a permitir a realização plena dos seus integrantes, seguindo o princípio constitucional da dignidade da pessoa humana.

Dentre as circunstâncias da parentalidade, a autoridade parental é merecedora de destaque, esta consiste no conjunto de direitos e obrigações inerentes aos pais com relação aos filhos menores de idade e não emancipados, art. 1.630 do Código Civil. Ainda que, a obsoleta nomenclatura pátrio poder, permaneça no Estatuto da Criança e do Adolescente, art. 21, e a terminologia poder familiar faz-se presente no atual Código Civil; a expressão autoridade parental, ganha destaque no Direito das Famílias, a julgar pela sua presença na legislação que dispõe sobre a alienação parental, Lei. $\mathrm{n}^{\mathrm{o}}$ 12.318/2010, e também no projeto de Lei $\mathrm{n}^{\circ}$ 470/2013 em defesa do Estatuto das Famílias, de autoria do Instituto Brasileiro de Direito de Família -IBDFAM e proposto pela senadora Lídice da Mata, em trâmite de aprovação no Senado.

Em decorrência das modificações afrontadas pela sociedade, torna-se cada vez mais comum a ruptura dos vínculos conjugais, muitas vezes lastreados por contendas envolvendo amarguras e rancor entre os consortes. Ressalta-se que, mesmo diante destas situações a autoridade parental permanece incólume, uma vez que a parentalidade não se confunde com a conjugalidade. Todavia, a modificação que se dá, diz respeito a uma das atribuições da autoridade parental, a guarda dos filhos; no sentindo jurídico, guarda é ato ou efeito de guardar e resguardar o filho enquanto menor de idade, de manter vigilância no exercício de sua custódia e de prestar-lhe a assistência necessária, no mais, a Constituição Federal em seu art. 229, assegura a toda criança o direito de ter um guardião para protegê-la.

Na legislação pátria, duas são as espécies de guarda de filhos, a unilateral e a guarda compartilhada. A guarda unilateral, consiste no exercício do direito/dever de guarda, de maneira direta, constante e com exclusividade por apenas um dos genitores, que residirá com os filhos, cabendo ao genitor não guardião o direito à convivência com à prole. No anseio de atenuar o impacto negativo que as desuniões impõe aos filhos e reduzir os efeitos patológicos das situações conflitivas, passou-se a admitir o compartilhamento da guarda, como forma de 
propiciar a continuidade da convivência entre os pais e filhos, preservando as relações de afeto existentes.

Por guarda compartilhada, entende-se a responsabilização conjunta pelo exercício de direitos e deveres por ambos os genitores, instituindo um sistema no qual os filhos e pais separados mantêm uma convivência harmoniosa, e todas as decisões referentes à prole são tomadas em conjunto. Tal instituto visa a participação dos pais em nível de igualdade nas decisões referentes aos filhos, sendo que estes permanecerão sob a guarda física atribuída a um dos genitores, porém, a guarda jurídica será exercida plenamente por ambos.

Embora já houvesse a concessão desta espécie de guarda, ela passou a ter previsão normativa apenas no ano de 2008, através da Lei n. 11.698, que modificou os arts. 1.583 e 1.584 do Código Civil, transformando a guarda compartilhada em guarda legal. Deste modo, a guarda unilateral deixa de ser o modelo exclusivo de custódia e passa a dividir o mesmo espaço jurídico que a guarda compartilhada, sendo esta orientada pelos princípios da igualdade, solidariedade e em especial pelo melhor interesse dos filhos.

Mais recentemente, foi aprovada a Lei $\mathrm{n}^{\mathrm{o}}$ 13.058, de 22 de dezembro de 2014, que provocou novas alterações nos dispositivos do Código Civil atinentes à atribuição da guarda de filhos, reforçando a guarda compartilhada como regra. Com o advento desta lei, fica ajustado que, quando não houver acordo entre os pais em relação ao sistema de guarda dos filhos, o juiz deverá aplicar a guarda compartilhada quando ambos os genitores estiverem aptos a exercer a autoridade parental, salvo se um deles declarar expressamente em juízo que não deseja a guarda do filho.

Os principais pontos polêmicos dessa inovação vêm dividindo opiniões entre os juristas. Muito se debate acerca da efetividade da guarda compartilhada e suas vantagens aos filhos, visto que muitas vezes os genitores encontram-se em meio às disputas e conflitos advindos da separação. Inúmeros são os prejuízos que os filhos poderão sofrer com a imposição obrigatória desta modalidade de guarda, caso não exista um relacionamento amigável entre os pais, restando a prole em estado de vulnerabilidade em face às disputas pessoais de ambos.

Outro ponto que levanta acalorada discussão, diz respeito à forma de divisão do tempo de permanência do filho com cada um dos genitores. O parágrafo segundo do art. 1.583, CC estabelece que na guarda compartilhada, o tempo de convívio com os filhos deverá 
ser dividido de maneira equilibrada entre pai e mãe, sempre tendo em vista as condições fáticas e os interesses da prole.

Considerando-se que na guarda compartilhada o que se divide é a guarda jurídica e não a custódia física dos filhos, a primeira impressão que se tem do instituto atribuído pela Lei $n^{\circ} 13.068 / 2014$ é de tratar-se de guarda alternada na qual os filhos residem determinado período com cada um dos genitores, dividindo-se a guarda material. Importante destacar que a modalidade de guarda alternada não é prevista pela legislação brasileira, justamente por ser prejudicial à criança/adolescente.

Desta feita, busca-se com o presente artigo uma melhor averiguação do instituto da guarda compartilhada obrigatória, dando ênfase aos pontos em dissenso pela doutrina, a fim de constatar a correta aplicabilidade da guarda conjunta, para que então, esta alcance seu objetivo maior, o melhor interesse da criança e do adolescente.

Destarte, o método escolhido para esta pesquisa foi o dedutivo, no qual realizou-se uma revisão da bibliografia referente ao Direito das Famílias e em especial aos institutos da autoridade parental e guarda compartilhada.

\section{AUTORIDADE PARENTAL}

A linha histórica da autoridade parental teve início no direito romano, naquela época, este instituto estava voltado para o regime patriarcal e era denominado de Pátrio Poder ou patria potestas em que o poder competia prioritariamente ao pai ou ao ascendente mais idoso da grei familiar, com poderes de regência da vida dos descendentes, esposa, agregados e escravos (Wald, 2000, p. 9).

No plano patrimonial, a prole não tinha direito a bens, sendo que todas as vantagens patrimoniais obtidas eram em benefício do pater familias, reunindo todo o patrimônio na pessoa do pai.

Com a promulgação do primeiro Código Civil brasileiro, em 1916, manteve-se a tradição do pater familias, considerando o marido o chefe da sociedade conjugal, já que a mulher casada era considerada relativamente incapaz, inferior por sua natureza, e submissa ao poder do varão. Mais adiante, em 1962, foi publicado o Estatuto da Mulher Casada, Lei $\mathrm{n}^{\circ}$ 4.121/62, que acarretou algumas modificações no Código Civil de 1916, acerca do pátrio poder. Neste sentido, foi atribuído o pátrio poder aos pais, sendo competente o marido, com o 
auxílio da esposa e, na falta ou impedimento de um, o outro passaria a exercê-lo com exclusividade.

Já em 1988 com a entrada em vigor da nova Carta Constitucional, as transformações do Direito de Família tornaram-se evidentes, sendo que grande parte dos artigos inseridos na Constituição Federal /88 com relação àquele Instituto, acarretaram a não recepção de mais de cem dispositivos do Código Civil de 1916 (COMEL. 2003. p. 40). Deste modo, o art. 5º I, da Constituição Federal (CF), consagrou como um direito fundamental, a isonomia de direitos e obrigações entre homens e mulheres, além disso, o art. 226, $\S 5^{\circ}$ deste mesmo dispositivo reforça este entendimento ao elencar o princípio da igualdade conjugal e parental. Destarte, a família patriarcal e a discriminação da mulher, evidente no Código Civil/16, mostrou-se inconciliável com as regras da Constituição Federal/88, cedendo lugar a uma sociedade familiar embasada no companheirismo e na igualdade dos pais frente ao pátrio poder.

Logo mais, veio o Estatuto da Criança e do Adolescente (ECA) Lei n. 8.069/90, que reafirmou a igualdade parental entre os genitores, estabelecendo que o pátrio poder deverá ser exercido conjuntamente pelo pai e pela mãe, art. 21: "O pátrio poder será exercido, em igualdade de condições, pelo pai e pela mãe, na forma do que dispuser a legislação civil, assegurado a qualquer deles o direito de, em caso de discordância, recorrer à autoridade judiciária competente para a solução da divergência."

Mesmo após tantas modificações acerca do Instituto Família e em especial com relação às funções parentais, a expressão pátrio poder continuava remetendo à superioridade do homem no âmbito familiar. Todavia, tal colocação não mais condizia com os reais parâmetros das relações familiares. Assim, buscou-se compatibilizar o Código Civil (CC) aos novos contextos jurídicos e valores da sociedade, restando neste momento sancionada a Lei $\mathrm{n}^{\mathrm{o}}$ 10.406 de janeiro de 2002, que deu origem ao novo Código Civil, que por sua vez, substituiu a figura do pátrio poder pelo poder familiar.

O poder familiar compreende a reunião dos direitos e deveres dos pais em relação aos filhos menores não emancipados, conforme preceitua o art. 1.630 do Código Civil/2002¹. Mostra-se fundamental a convivência e a participação dos membros do grupo familiar, no sentido de efetivar o princípio do melhor interesse da criança e do adolescente, tendo em conta que estes são incapazes de prover suas necessidades, carecendo que alguém o faça. Deste modo, os direitos e obrigações inerentes às funções parentais visam à formação integral

${ }^{1}$ Art. 1.630, Código Civil, “Os filhos estão sujeitos ao poder familiar, enquanto menores.” 
dos filhos, seja ela, física, mental, moral, espiritual, social, ou seja, tudo o que necessário for para uma vivência sadia, realizada e completa.

Maria Helena Diniz (2010, p. 564) assim define o poder familiar:

Conjunto de direitos e obrigações, quanto à pessoa e bens do filho menor não emancipado, exercido, em igualdade de condições, por ambos os pais, para que possam desempenhar os encargos que a norma jurídica lhes impõe, tendo em vista o interesse e a proteção do filho.

Ressalta-se que a alteração da terminologia não demonstra a criação de um novo instituto jurídico, mas uma nova denominação adaptada ao texto constitucional e compatibilizada com o avanço marcante e profundo da sociedade global (AKAEL, 2009, p. 9). No mais, a expressão poder familiar evidencia a igualdade entre os genitores, conferindolhes o exercício simultâneo e conjunto da incumbência legal imposta pelo próprio Estado.

Embora seja indiscutível o avanço alcançado com esta nova denominação designada pelo legislador, muitos são os defensores de que a nomenclatura poder familiar ainda não é a mais adequada, e sim "autoridade parental", por refletir a profunda mudança que resultou da consagração constitucional do princípio da proteção integral da criança/adolescente (DIAS, 2015, p. 461).

Silvio Rodrigues (2008, p. 355) é um dos críticos do termo poder familiar, segundo o jurista, o legislador se preocupou mais em retirar da expressão a palavra pátrio do que incluir o seu real conteúdo, que, antes de um poder, representa a obrigação/dever dos genitores, e não da família propriamente dita, como o nome induz. Neste sentido, o vocábulo "autoridade" exprime de maneira mais clara o sentido do exercício, da função e do dever desempenhado pelos pais, e o termo "parental" melhor revela a relação de parentesco entre pais e filhos, destinatários desse poder/dever (AKAEL, 2009, p. 10).

Além disso, o fato de caracterizar um poder, não significa arbitrariedade, mas um composto de autoridade e obrigação, assim, os genitores têm dever de desempenhar a autoridade parental tendo em vista, tão somente, o benefício dos filhos, em razão de sua experiência e amadurecimento em face destes.

Conquanto, a nomenclatura pátrio poder, já em desuso, permaneça no Estatuto da Criança e do Adolescente, e a terminologia poder familiar faz-se presente no atual Código Civil; os reflexos da defesa da expressão autoridade parental, começam a surgir, bastando ver a sua presença na legislação que dispõe sobre a alienação parental, Lei. n. 12.318/2010, ao incluir no rol dos procedimentos censuráveis a campanha de desqualificação da conduta dos 
pais no exercício da autoridade parental ${ }^{2}$. No mais, o projeto de Lei n. 470/2013, idealizado pelo Instituto Brasileiro de Direito de Família -IBDFAM e proposto pela senadora Lídice da Mata, que tramita no Senado, em defesa da criação do Estatuto das Famílias, deixa em destaque o capítulo da autoridade parental, arts. 89 a 98, incumbindo aos pais o dever de assistência moral e material, cuidado, educação e formação dos filhos menores, a ser exercido sempre buscando o melhor interesse dos filhos.

Ainda que a autoridade parental seja reconhecida como um instituto de caráter protetivo, composto por um conjunto de deveres em relação aos filhos, expresso no art. 1.634, $\mathrm{CC}$, este rol não consta o que sem dúvidas é considerado o maior dever dos pais: o dever de lhes dar amor, afeto e carinho (DIAS, 2015, p. 465).

\section{PROTEÇÃO E O MELHOR INTERESSE DAS CRIANÇAS E DOS ADOLESCENTES}

O princípio do melhor interesse das crianças e dos adolescentes é garantidor da efetivação dos direitos fundamentais destes, tratando-se de uma franca materialização da teoria da proteção integral, presente no art. 227 da Constituição Federal ${ }^{3}$ e art. $1^{\circ}$ do Estatuto da Criança e do Adolescente. ${ }^{4}$ No mais, o art. $4^{\text {o }}$ do ECA enfatiza que o suporte às crianças/adolescentes constitui dever da família, da comunidade, da sociedade em geral e inclusive do Poder Público, devendo ser priorizada a efetivação dos direitos essenciais à vida, à saúde, à alimentação, à educação, ao esporte, ao lazer, à profissionalização, à cultura, à dignidade, ao respeito, à liberdade e à convivência familiar e comunitária (OLIVEIRA, 2015, p. 319).

Além destes dispositivos presentes no ordenamento jurídico brasileiro, a respeito da proteção integral, a Convenção das Nações Unidas sobre os Direitos da Criança de 1989, também mostrou-se pioneira nesta questão, ao determinar em seu art. $3^{\circ}$ a aplicação do princípio basilar do maior interesse, não apenas pelas famílias, mas sim por todas as instituições públicas e privadas, assegurando às crianças e aos adolescentes as condições de

\footnotetext{
${ }^{2}$ Lei. $n^{\circ}$ 12.318/2010. Art. $3^{\circ}$ : A prática de ato de alienação parental fere o direito fundamental da criança ou do adolescente de convivência familiar saudável, prejudica a realização de afeto nas relações com o genitor e com o grupo familiar, constitui abuso moral contra a criança ou o adolescente e descumprimento dos deveres inerentes à autoridade parental ou decorrentes de tutela ou guarda. (gn)

3 Art. 227, Constituição Federal: É dever da família, da sociedade e do Estado assegurar à criança e ao adolescente, com absoluta prioridade, o direito à vida, à saúde, à alimentação, à educação, ao lazer, à profissionalização, à cultura, à dignidade ao respeito, à liberdade e à convivência familiar e comunitária, além de colocá-los a salvo de toda forma de negligência, discriminação, exploração, violência, crueldade e opressão.

4 Art. $1^{\mathrm{o}}$, do Estatuto da Criança e do Adolescente: Esta Lei dispõe sobre a proteção integral à criança e ao adolescente.
} 
um desenvolvimento saudável, mediante a livre manifestação dos seus direitos, opiniões e desejos, para que se integrem dentro do seu universo comunitário.

Ademais, o Código Civil/2002 criou um capítulo próprio para tratar da proteção da pessoa dos filhos, arts. 1.583 a 1.580, nas situações de separação/divórcio dos genitores, instituindo regras de convivência parental que se efetivarão de acordo com as modalidades de guarda existentes, devendo estas serem fixadas a fim de bem atender ao melhor interesse dos filhos.Para Eduardo de Oliveira Leite (2003, p. 197):

\begin{abstract}
O interesse do menor serve, primeiramente, de critério de controle, isto é, de instrumento que permite vigiar o exercício da autoridade parental sem questionar a existência dos direitos dos pais. Assim, na família unida, o interesse presumido da criança é de ser educado por seus pais, mas, se um deles abusa ou usa indevidamente suas prerrogativas, o mesmo critério permitirá lhe retirar, ou controlar mais de perto, o exercício daquela direito. O interesse do menor é utilizado, de outro lado, como critério de solução, no sentido que, em caso de divórcio, por exemplo, a atribuição da autoridade parental e do exercício de suas prerrogativas pelos pais depende da apreciação feita pelo juiz do interesse do menor.
\end{abstract}

Sabe-se que o princípio da integral proteção dos filhos deve ser respeitado em todos os momentos de suas vidas, e não apenas quando ocorre a ruptura das relações conjugais, entretanto, vale ressaltar que é exatamente nestas situações que busca-se o efetivo cumprimento deste princípio, justamente pelo fato de que a ruptura diz respeito apenas à conjugalidade e jamais à parentalidade.

\title{
4 MODALIDADES DE GUARDA E CONVIVÊNCIA FAMILIAR
}

De maneira genérica, o significado da palavra "guarda" é utilizado para demonstrar ato ou efeito de proteção, observância, vigilância ou segurança (SILVA, 1994, pp. 365, 366). Tais acepções também são empregadas pelo Código Civil e pelo Estatuto da Criança e do Adolescente, sendo que nestes Institutos o vocábulo guarda está intimamente relacionado ao poder familiar, conferindo aos genitores caráter de posse do filho menor de idade. ${ }^{5}$

Com relação à guarda de filhos, prevalece um direito/dever natural, que origina-se da paternidade/maternidade, partindo de um pressuposto de convivência com a prole, o que torna possível o exercício de todas as funções parentais elencadas pelo Código Civil e Estatuto da Criança e do Adolescente. Esta forma de guarda que nasce de maneira natural com a parentalidade, sem intervenção judicial é conhecida por guarda originária ou comum.

\footnotetext{
${ }^{5}$ Cf. arts 1.634, II, Código Civil, 21 e 22, Estatuto da Criança e Adolescente.
} 
Em decorrência das transformações enfrentadas pela sociedade, torna-se cada vez mais comum a ruptura dos vínculos conjugais, muitas vezes lastreados por conflitos envolvendo mágoas e rancor entre os cônjuges. É justamente neste momento que surge a necessidade da aplicação judicial da guarda de filhos, inclusive com respaldo legal da Constituição Federal que em seu art. 229, assegura a toda criança o direito de ter um guardião para protegê-la.

A doutrina contemporânea, em especial o Instituto Brasileiro de Direito de Família IBDFAM, defende a necessária adequação da expressão convivência familiar em substituição ao termo guarda, que pode causar falsa impressão de "disputa" por um objeto, o que não apresenta uma compatibilidade com os avanços sociais, que devem ser orientados sempre pela busca do melhor interesse da criança e do adolescente, pois independentemente do modelo de guarda escolhido ou imposto, os filhos deverão ter resguardado o direito de convivência com ambos os genitores.

Em decorrência deste posicionamento, o Estatuto das Famílias que está em trâmite de aprovação no Senado, provoca a substituição da palavra guarda por convivência familiar, criando então, um capítulo que tratará dos deveres e direitos inerentes aos pais, sempre com a intenção de resguardar a convivência ampliada destes com a prole.

No mais, a expressão convivência familiar também é utilizada para referir-se ao direito de visitas concedido àquele genitor que não detém a guarda física do filho. Nestas situações o relacionamento entre o progenitor não guardião e a prole deve ser preservado, mesmo quando estes não vivem sob o mesmo teto. Objetivando-se a consagração do princípio da proteção integral, em vez de regulamentar as visitas, faz-se necessário estabelecer formas de convivência, pois não há proteção possível com a exclusão do outro genitor (DIAS, 2015, p. 532).

Neste sentido, seguem os ensinamentos da ilustre Maria Berenice Dias (2015, p. 532):

Escassa, para não dizer inexistente, é a regulamentação do direito de convivência no Código Civil - que todos insistem em chamar de direito de visitas, expressão de todo inadequada, pois os encargos inerentes ao poder familiar não se limitam a assegurar ao genitor o direito de ter o filho em sua companhia em determinados períodos de tempo. A locução de visitas evoca uma relação de índole protocolar, mecânica, como uma tarefa a ser executada entre ascendente e filho, com as limitações de um encontro de horário rígido e de tenaz fiscalização. 
Vale ressaltar que o direito de convivência não é assegurado apenas aos genitores, trata-se de direito do próprio filho de com eles conviver, inserido dentre os direitos da personalidade, é direito da criança/adolescente manter contato com o genitor com o qual não convive diariamente, tornando-se dever dos pais a concretização deste direito.

\subsection{GUARDA UNILATERAL}

A guarda unilateral, também conhecida por uniparental consiste no exercício do dever/direito de guarda, de maneira direta, constante e com exclusividade por apenas um dos genitores. Embora este não seja o único modelo de guarda existente no ordenamento jurídico brasileiro, ainda é o mais utilizado, seja pela escolha dos genitores ou por decisão judicial. Está previsto no art. 1.583 do Código Civil, sendo que o parágrafo primeiro deste mesmo dispositivo c/c o parágrafo quinto do art. 1.584, permitem que a guarda seja confiada a terceiros, em substituição aos genitores, assim, é possível que a autoridade parental permaneça com os pais e a guarda com um terceiro que deve ser escolhido pela relação de parentesco e afinidade com a criança/adolescente (VIANA, 1993, p. 38).

Nas situações de guarda uniparental, os filhos residem com o genitor guardião, que lida com as ocorrências cotidianas da prole, ou seja, toma decisões com relação aos filhos menores de maneira unilateral. Entretanto, o genitor não guardião continua no exercício da autoridade parental, deste modo, o parágrafo quinto do art. 1.583, Código Civil, impõe a este progenitor o dever de supervisionar os interesses da prole, tendo ele legitimidade para requerer informações sobre a saúde física/psicológica e a educação de seus filhos, para qualquer estabelecimento público ou particular, devendo as informações serem prestadas de prontidão, inclusive sob pena de multa diária ${ }^{6}$. O peso das astreintes objetiva obter o pronto atendimento das informações devidas aos pais, com relação aos filhos, atingindo principalmente as instituições escolares que estes frequentam.

Ademais, também é atribuído ao genitor não guardião, o direito de visitação e convivência familiar, que poderá ser pré-fixado de maneira consensual entre os genitores ou, caso necessário, por decisão judicial. Todavia, o papel de visitante imposto a um dos progenitores, além de estigmatizá-lo, poderá acarretar um distanciamento afetivo entre este e o filho, além do que a posição vivenciada pelo genitor visitante é deveras inferiorizada frente

\footnotetext{
${ }^{6}$ Art. 1.584, $\S 6^{\circ}$, Código Civil: qualquer estabelecimento público ou privado é obrigado a prestar informações a qualquer dos genitores sobre os filhos destes, sob pena de multa de $\mathrm{R} \$ 200,00$ (duzentos reais) a $\mathrm{R} \$ 500,00$ (quinhentos reais) por dia pelo não atendimento da solicitação.
} 
à colocação experimentada pelo genitor guardião, responsável por comandar a vida do filho. (ZAMARIOLA; CAMARGO; OLIVEIRA, jan./fev. 2015, p. 31).

Muitas vezes a disputa de guarda de filhos os colocam em situações altamente prejudiciais, haja vista que os pais acabam por utilizar os seus filhos como se fossem moeda de troca, sendo estes considerados troféus para aquele genitor que venceu a disputa e foi empossado como guardião. Além disso, a guarda unilateral é considerada desvantajosa, pois na maioria dos casos, os filhos desejam estar ao lado de seu pai e de sua mãe de maneira igualitária, e não estar com um, e receber a visita do outro, desta forma ocorre o afrontamento ao princípio do melhor interesse da criança.

\subsection{GUARDA ALTERNADA}

A guarda alternada também conhecida por guarda dividida, consiste num revezamento do exercício da guarda unilateral, ou seja, se caracteriza pela possibilidade de cada um dos genitores deter a guarda do filho com exclusividade, porém, de maneira rotativa, durante certo período, que poderá ser anual, semestral, mensal, ou até mesmo em dias alternados. A característica predominante desta modalidade de guarda, é justamente a concentração com exclusividade dos poderes/deveres próprios da autoridade parental na figura de apenas um dos genitores, no momento em que se encontra na sua vez de revezamento.

Conforme se verifica, nesta modalidade de guarda, há uma divisão igualitária do tempo de convívio com a prole, acarretando na divisão e exercício da guarda física, ou seja, a criança hora fica na casa da mãe, hora permanece na residência do pai. No mais, também ocorre a divisão temporal no aspecto jurídico, que diz respeito às decisões acerca da prole, que podem envolver questões educacionais e inclusive de saúde e bem estar.

A alternância de guarda também é considerada prejudicial aos filhos, na medida em que impede o alicerçamento das bases de formação da criança/adolescente em decorrência do constante revezamento de orientações a que estes são submetidos. Além de que, transforma os filhos em verdadeiros ioiôs que são jogados de "lá pra cá" e vice versa, ferindo o princípio do melhor interesse da criança e adolescente. Precisamente por estas características altamente maléficas, o direito pátrio não prevê a guarda alternada dentre a sua legislação, no entanto, 
sta merece destaque tendo vista sua constante confusão com a guarda compartilhada (OLIVERA, 2015, p. 334).

\subsection{GUARDA COMPARTILHADA}

Por fim, a guarda compartilhada consiste na responsabilização conjunta pelo exercício de direitos e deveres por ambos os genitores, instituindo um sistema no qual os filhos e pais separados mantêm uma convivência harmoniosa, e todas as decisões referentes à prole são tomadas em conjunto. Vale destacar, que a guarda compartilhada esta relacionada à custódia jurídica dos filhos, ou seja, o que deve ser compartilhado são as responsabilidades decorrentes da parentalidade. Com relação à guarda física ou material, esta permanece com um dos genitores, tendo em conta que a criança/adolescente terá uma residência como referência, no mais, será compartilhada a convivência entre pais e filhos, desde que seja respeitado os limites e necessidades destes.

Embora já houvesse a concessão desta espécie de guarda, ela foi inserida no ordenamento jurídico brasileiro, apenas no ano de 2008, através da Lei n. 11.698, de 13 de junho de 2008, que modificou os arts. 1.583 e 1.584 do Código Civil, transformando a guarda compartilhada em guarda legal. Deste modo, a guarda unilateral deixa de ser o modelo exclusivo de guarda e passa a dividir o mesmo patamar normativo que a guarda compartilhada, sendo esta orientada pelos princípios da igualdade, solidariedade e em especial pelo melhor interesse da criança/adolescente.

De acordo com as alterações da Lei 11.698/2008, o art. 1.584, CC determina que tanto a guarda unilateral, quanto a guarda compartilhada poderão ser estabelecidas de maneira consensual entre os genitores (inciso I), ou por determinação judicial (inciso II). No mais, ficou a cargo do magistrado o dever de esclarecer aos pais o significado da guarda compartilhada, bem como a sua importância $\left(\S 1^{\circ}\right)$, além disso a legislação manifestou clara preferência pela guarda conjunta, ao mencionar que quando os acordos restarem infrutíferos, a guarda compartilhada será aplicada sempre que possível, considerando as necessidades específicas da criança/adolescente e seu melhor interesse e proteção $\left(\S 2^{\circ}\right)$.

Mesmo após o nascimento da guarda compartilhada legal, a guarda unilateral permaneceu como o modelo tradicional, tendo em vista que prevaleceu entre os doutrinadores o posicionamento de que a fixação da guarda compartilhada pelo juiz, apenas deverá advir nas situações em que prepondera a harmonia e o diálogo entre os genitores. 
Portanto, nos casos em que não houver o consenso entre os pais, é aconselhável que o filho permaneça sob a guarda unilateral, que deverá ser atribuída àquele genitor que demonstrar melhor condição de exercê-la.

Com a predominância deste entendimento, a aplicação prática do instituto da guarda conjunta, mostrou-se em dificuldade, pois são raros os casais que conseguem manter um bom relacionamento após a ruptura do vínculo conjugal. Neste sentido, Waldir Grisard Filho (2014, p. 198) defende a necessidade de adotar uma nova regra que permita a aplicação da guarda compartilhada mesmo quando as separações/divórcios terminem em litígio, não podendo a escolha do modelo de guarda depender da autoridade dos pais, pois o que deve prevalecer é o melhor interesse dos filhos.

Em decorrência deste posicionamento, defendido não apenas pelo autor acima citado, mas também por outros estudiosos do Direito de Família, em dezembro de 2014, foi sancionada outra legislação sobre a guarda compartilhada, que eleva esta modalidade de guarda ao patamar de obrigatoriedade, por isso a Lei 13.068/2014 é conhecida como a legislação da guarda compartilhada obrigatória.

\section{GUARDA COMPARTILHADA OBRIGATÓRIA E O MELHOR INTERESSE DOS FILHOS}

Em decorrência do sancionamento da nova legislação sobre guarda compartilhada, os arts. $1.583,1.584,1.585$ e 1.634 do Código Civil sofreram alterações, e passaram a disciplinar com largueza a maneira de proteger a pessoa dos filhos nos casos que acarretam o fim da conjugalidade. Tais dispositivos dão precedência à guarda compartilhada como norma geral, e definem as providências jurídicas relacionadas à sua regulamentação, que deverão ser precedidas de audiência de conciliação e com apoio técnico de equipe multidisciplinar composta por psicólogos e assistentes sociais.

De acordo com a interpretação da lei e a doutrina predominante, a guarda conjunta deixou de ser uma questão de opinião ou de preferência, tornando-se uma imposição legal, que deverá ser atribuída mesmo contra a vontade dos genitores e o eventual estado de beligerância entre eles, art. 1.584, $\S 2^{\circ}$, CC. Diante do dispositivo legal de aplicação prioritária da guarda compartilhada, considera-se exceção à regra apenas as situações na quais ocorra a declaração de desinteresse por parte de ao menos um dos genitores. Todavia, a negativa do compartilhamento também deverá ocorrer em outras circunstâncias que poderão obstaculizar a efetivação deste regime de guarda, como a ausência de um dos genitores, 
doença grave, comprovado desvio de conduta, prisão dentre outras situações, sendo que estas deverão ser devidamente examinadas na instrução processual.

O instituto da guarda compartilhada busca a efetivação do princípio da igualdade parental entre genitores separados, divorciados ou por qualquer motivo impedidos de uma convivência regular com os filhos. Conquanto o texto legal implica a sua aplicabilidade independentemente de contendas entre os genitores, é indiscutível que a efetividade da guarda conjunta depende das circunstâncias do comportamento pessoal e da disposição de cada um dos pais, que necessitam de uma abertura maior ao diálogo nas decisões compartilhadas. Embora diante à superioridade da guarda conjunta, sua imposição coercitiva pelo magistrado nem sempre refletirá boa solução, em especial nos casos onde prevalece forte litígio entre os genitores.

Deste modo, não se afigura adequado dizer que a guarda compartilhada disputada por ambos os pais seja obrigatória, ao contrário disto, a guarda conjunta deverá, sempre que possível, ser recomendada e preferível, assim, mostra-se mais adequada a antiga redação do artigo 1.584, § $2^{\circ}$, CC; sendo que é proporcionado ao magistrado a abertura para julgar de acordo com os interesses e direitos das partes, devendo-se destacar que o interesse que deverá prevalecer é o dos filhos, e justamente por esta razão, em situações que denotem a inconveniência da adoção da guarda compartilhada, esta jamais poderá ser aplicada compulsoriamente (OLIVEIRA, 2015, p. 332).

Outro ponto que levanta acalorada discussão, diz respeito à forma de divisão do tempo de permanência do filho com cada um dos genitores, o $\S 2^{\circ}$ do artigo $1.583, \mathrm{CC}$ estabelece que na guarda compartilhada, o tempo de convívio com os filhos deve ser dividido de maneira equilibrada entre os pais, sempre tendo em vista as condições fáticas e os interesses da prole. Neste mesmo aspecto, a parte final do $\S 3^{\circ}$ do art. 1.584, CC, também faz referência à divisão equilibrada do tempo entre o pai e a mãe.

Levando-se em consideração que na guarda compartilhada o que se divide é a guarda jurídica e não a custódia física dos filhos, a primeira impressão que se tem do instituto atribuído pela Lei n. 13.068/2014 é de que trata-se de guarda alternada, anteriormente abordada neste trabalho, na qual os filhos habitam determinado período com cada um dos genitores, dividindo-se a guarda física. Vale ressaltar que a modalidade de guarda alternada não é prevista na legislação brasileira justamente pela sua prejudicialidade à criança/adolescente. Este também é o entendimento de Waldyr Grisard Filho (2015, p. 12) "a 
norma projetada não só mantém vivos alguns velhos equívocos à sua atribuição como ressuscita outros, de nefasta memória, como a guarda alternada, nunca disciplinada em nosso ordenamento jurídico. Assim, a guarda compartilhada permanece na berlinda".

Por sua vez, a juíza Ângela Gimenez ${ }^{7}$, grande defensora da guarda compartilhada obrigatória alega que a confusão entre esta espécie de guarda e a guarda alternada, não passa de um erro grosseiro, considerando-se que esta constitui em uma guarda unilateral, caracterizada pelo desempenho exclusivo da guarda por um dos genitores segundo um período predeterminado que pode ser anual, semestral ou diário, nos quais os filhos se submetem a uma alternância sistematizada de convivência.

Embora, esteja correta a diferenciação feita pela magistrada com referência às guardas alternada e compartilhada, a própria juíza se contradiz ao defender veementemente a distribuição equitativa de tempo da criança com o pai e com mãe, chegando ao extremo de alegar que "cabe ao juiz trabalhar com o ideal de compartilhamento na proporção de $50 \%$ do tempo de cada um dos genitores" (GIMENEZ, 2015, p. 7). No mais, também é de entendimento da magistrada que em situações nas quais os genitores residam em cidades diferentes ou em locais muito distantes, a equação distributiva do tempo poderá ser calculada de maneira distinta, desde que o percentual atinja ao menos $35 \%$ do tempo, caso contrário significará a guarda unilateral, se desfazendo a característica do compartilhamento.

De maneira contrária, busca-se esclarecer que a nova legislação não obriga um revezamento de moradia entre a casa do pai e a da mãe, cuida-se de uma divisão balanceada das responsabilidades, onde as decisões relativas aos filhos deverão ser compartilhadas como por exemplo, qual escola as crianças vão estudar, qual será o plano de saúde ou as atividades extracurriculares que vão praticar, até assuntos mais corriqueiros, como se a criança poderá ou não ir a uma excursão escolar. De tal modo segue o posicionamento da psicóloga Rosely Sayão (2015, p. 10) em entrevista ao IBDFAM: "Pai tem um jeito e mãe tem outro. Não podemos somar o tempo e dizer que é um tempo com o pai e outro com a mãe. Não se trata disso. É quase como dizer de uma responsabilidade compartilhada".

\footnotetext{
${ }^{7}$ Juíza titular da Primeira Vara Especializada em Família e Sucessões de Cuiabá e Presidente do IBDFAM-MT.
} 
A necessária cooperação entre os pais não se estabelece pela tentativa em homogeneizar as diferenças e dividir o tempo e moradia, pelo contrário, isto pode vir a acentuar a competição e as divergências. Em resumo, o risco é o de se privilegiar fatores espaciais e temporais objetivos, em detrimento dos fatores existenciais e afetivos, certamente mais complexos e valoráveis. Também em defesa de uma melhor interpretação da questão temporal que envolve a guarda compartilhada obrigatória, Gisele Câmara Groeninga (2014), psicanalista membro do IBDFAM, posiciona-se da seguinte maneira:

\begin{abstract}
Examine-se o que se afigura como uma confusão quanto ao significado de "divisão equilibrada do tempo". É importante que esta se dê "sempre tendo em vista as condições fáticas e os interesses dos filhos",como consta do PL. Condições e interesses que variam em cada fase do desenvolvimento das crianças e adolescentes, como também de acordo com as possibilidades dos pais, levando-se em conta o exercício diferenciado das funções. Caso as condições e interesses não recebam o necessário exame,e a continuar a confusão divulgada na mídia e nas críticas ao PL, em que se entende que os filhos passarão igual período na casa de cada genitor, a lei pode acabar por não atender aos interesses da família transformada pela separação dos cônjuges, conviventes, ou mesmo nos casos de filhos de casais que não se constituíram.
\end{abstract}

Deveras a guarda compartilhada seja o modelo ideal para que haja uma maior participação dos pais na vida de seus filhos, esta deverá ser aplicada com extrema delicadeza, fazendo-se importante a determinação judicial de estudo psicossocial com acompanhamento das partes, a fim de que nos casos de litígio, o juiz possa decidir de maneira fundamentada não apenas na legalidade, mas numa pesquisa das efetivas condições dos pais para o desenvolvimento da guarda conjunta.

No mais, o sentido e o implemento da convivência compartilhada, pressupõe entendimento entre os genitores para o desempenho uniforme e harmônico dos direitos e deveres entre pais e filhos, atendendo ao preceito constitucional da igualdade entre os genitores e da integração da criança/adolescente na esfera familiar. Destarte, tem-se como regra maior a aplicação da guarda conjunta, desde que haja conveniência para as partes envolvidas, tendo por fundamento as condições pessoais do pai ou da mãe sempre resguardando o superior interesse dos filhos.

De tal modo, partindo do princípio de que ambos são pais e devem se respeitar, superando as mágoas e rancores pelo fim da união conjugal, a fim de exercer o poder/dever em igualdade de condições, não há qualquer empecilho em estabelecer moradia fixa para os filhos, determinando-se que a administração dos filhos ficará a cargo de ambos os genitores, pois mesmo que um dos genitores não resida com a prole, ele poderá levá-los ou buscá-los na escola, auxiliá-los nas tarefas diárias, participar em reuniões pedagógicas e de eventos 
desportivos, levá-los ao médico, enfim, terá a oportunidade de integrar-se na vida dos filhos, ensinando-lhes, por suas atitudes, os supremos valores à formação psicossocial, pois, vale lembrar que pai e mãe continuam identicamente responsáveis pela educação e pelo desenvolvimento psíquico e moral dos filhos.

Diante de todo o estudo relacionado à guarda compartilhada, sabe-se que este modelo realmente é o que melhor atende aos interesses dos filhos, pois, estes terão a oportunidade de conviver com ambos os genitores, sem a necessidade de escolhas. Porém, não pode-se negar que a efetividade prática deste instituto é amplamente dependente daqueles que conduzirão esta custódia, ou seja, os pais. Por isso a grande crítica quanto à aplicabilidade compulsória da guarda compartilhada não diz respeito às disputas entre os genitores, mas sim, quanto ao efetivo cumprimento da proteção e do melhor interesse dos filhos.

Outrossim, vale destacar que o regime de guarda escolhido ou determinado subsiste enquanto atender ao melhor interesse da criança/adolescente. Deste modo, poderá ser modificado a qualquer momento por acordo dos genitores ou por determinação judicial.

\section{CONCLUSÃO}

Embora a guarda compartilhada seja aplicada há tempos no Brasil, sua previsão legal deu-se apenas em 2008, através da Lei $\mathrm{n}^{\circ}$ 11.698. A partir deste momento, a guarda unilateral passou a dividir o mesmo patamar jurídico que a guarda compartilhada, no entanto, devido aos costumes e as dificuldades encontradas para a efetividade desta, a guarda unilateral permaneceu como modelo tradicional de custódia.

Com a intenção de criar novos paradigmas com relação à aplicabilidade da guarda conjunta, criou-se a Lei $\mathrm{n}^{\mathrm{o}}$ 13.058/2014 conferindo-lhe o caráter de obrigatoriedade, mesmo quando não houver consenso entre os genitores. Tais alterações, provocaram grande discussão na doutrina, uma vez que torna-se indiscutível a efetividade da guarda conjunta como dependente das circunstâncias comportamentais e da solicitude de cada um dos pais, que necessitam de um contato mais próximo e respeitoso para as decisões compartilhadas.

Também com relação à guarda compartilhada obrigatória, apresenta-se outra problemática no que diz respeito à menção a uma custódia física dividida, que se confunde com a ideia de guarda alternada e não compartilhada, sendo aquela considerada nociva à formação dos filhos ante a supressão das referências básicas, opondo-se ao princípio da 
ontinuidade, já que a criança/adolescente irá conviver sob a responsabilidade de cada guardião alternadamente dentro de tempo determinado.

Contrapondo-se à guarda alternada, no compartilhamento da guarda, a custódia física dos filhos ficará com um dos genitores, enquanto a guarda jurídica será exercida por ambos os pais. Nesta modalidade de guarda, assegura-se aos filhos uma residência fixa como ponto de referência, a ser escolhida em consenso pelos genitores ou proposta pelo juiz, sempre buscando atender às necessidades dos filhos. Quanto ao genitor que não resida com a prole, deverá participar ativamente na formação desta, responsabilizando-se conjuntamente por todos os aspectos da vida dos filhos.

Desta feita, para que a aplicabilidade da guarda compartilhada ocorra de maneira saudável, mesmo havendo descontentamento em relação às condutas conjugais, faz-se imprescindível a colaboração dos ex-consortes, em nome do melhor interesse dos filhos, para que então possam ser tomadas as melhores decisões acerca da prole.

Deste modo, a imposição coercitiva pelo magistrado nem sempre refletirá boa solução, em especial nos casos onde prevalece forte litígio entre os genitores, de tal sorte que pode vir a ser relegada à margem das decisões impraticáveis.

\section{REFERÊNCIAS}

AKAEL, Ana Carolina Silveira. Guarda compartilhada: um avanço para a família. 2. ed. São Paulo: Atlas, 2009.

ALVES, Leonardo Barreto Moreira. A guarda compartilhada e a Lei n. 11.698/2008. Revista IOB de Direito de Família.ano IX. n. 51. Porto Alegre: Síntese, dez-jan 2009.

AMARAL, Paulo André. Guarda compartilhada, igualdade de gênero e justiça no brasil: uma análise das interpretações da lei. Revista Brasileira de Direito de Família e Sucessões. Porto Alegre: Magister; Belo Horizonte: IBDFam, a. 14, n. 32. fev. e mar. 2013.

COMEL, Denise Dano. Do poder familiar. São Paulo: Revista dos Tribunais, 2003.

CONTIJO, Sigismundo. Guarda de filhos. Pai Legal, 22 de mai. 2003. Disponível em <http://www.pailegal.net/forum/viewtopic.php?t=756>. Acesso em: 20 de maio de 2014.

DIAS, Maria Berenice. Manual de direito das famílias. 10. ed. São Paulo: Revista dos Tribunais, 2015. 
DINIZ, Maria Helena. Curso de direito civil brasileiro: direito de família. v.5. 25. ed. São Paulo: Saraiva, 2010.

GAMA, Guilherme Calmon Nogueira. Princípios constitucionais de direito de família. São Paulo: Atlas, 2008.

GAMA, Ricardo Rodrigues. Guarda compartilhada: lei n. 11.698, de 13 de junho de 2008. Campinas: LZN, 2008.

GIMENEZ, Angela. Igualdade parental. Entrvista. In: Revista IBDFAM. Guarda compartilhada, lei sancionada em dezembro tem como objetivo garantir a igualdade parental. 2015.

GRISARD FILHO, Waldir. A guarda compartilhada na berlinda. In:. 2015. 2014.

Guarda compartilhada. 7. ed. rev. atual. e ampl. São Paulo: Revista dos Tribunais,

GROENINGA, Gisele Câmara. Guarda compartilhada e relacionamento familiar: algumas reflexões necessárias. Disponível em: <http://ibdfam.org.br/artigos/996/Guarda+Compartilhada+e+Relacionamento+Familiar +\% E2\% 80\% 93+Algumas+Reflex\% C3\% B5es+Necess\% C3\%A1rias+>. Acesso em: 29 de fevereiro de 2016.

; PEREIRA, Rodrigo da Cunha. Família: um caleidoscópio de relações, em direito de família e psicanálise, rumo a uma nova epistemologia. Rio de Janeiro: IMAGO, 2008.

LEITE, Eduardo de Oliveira. Famílias monoparentais. São Paulo: Revista dos Tribunais, 2003.

OLIVEIRA, Euclides. Alienação parental e nuances da parentalidade: guarda e convivência familiar. In: PEREIRA, Rodrigo da Cunha (organizador). Tratado de direito das famílias

RODRIGUES, Silvio. Direito civil: direito de família. 28 ed. São Paulo: Saraiva, 2008. v. 6.

SANTOS, Bruna Mattos dos. A aplicabilidade da guarda compartilhada em face da alienação parental. Monografia de Direito. $116 \mathrm{f}$. Franca: Universidade Estadual Paulista. Faculdade de Ciências Humanas e Sociais, 2015.

SAYÃO, Roseli. Direito à convivência familiar. Entrevista. In: Revista IBDFAM. Guarda compartilhada, lei sancionada em dezembro tem como objetivo garantir a igualdade parental. 2015.

SILVA, De Plácido. Vocabulário jurídico. 4 ed. Rio de Janeiro: Forense, 1994.

VIANA, Marco Aurélio S. Da guarda, da tutela e da adoção. Belo Horizonte: Del Rey, 1993.

WALD, Arnoldo. O novo direito de família. 13. ed. rev. atual. amp. São Paulo: Saraiva, 2000. 
ZAMARIOLA, Aldrin Teubl Sanches; CAMARGO, Daniela Romano Tavares; OLIVEIRA, Glauber Vinícius Vieira de. Análise da obrigatoriedade da guarda compartilhada e as relações nas famílias brasileiras: a lei n. 13.058/2014. In: Revista Nacional de Direito de Família e Sucessões. Porto Alegre: Magister, jan./fev. 2015. 